\title{
Breyten Breytenbach in een zijspiegel: Het vizier van H.C. ten Berge Transnationale laterale beweging en particuliere "hetero-images" van een literaire actor
}

\author{
YVES T'SJOEN \\ Ghent University \\ University Stellenbosch \\ Vakgroep Letterkunde, Afdeling Nederlands \\ Universiteit Gent \\ Blandijnberg 2 \\ B-9000 Gent, België \\ Departement Afrikaans en Nederlands \\ Universiteit Stellenbosch \\ Letteregebou - Privaat Sak X1 \\ Matieland 7602, South Africa \\ Yves.TSjoen@UGent.be
}

\section{Breyten Breytenbach Through H.C. ten Berge's Looking-Glass: Transnational Lateral Movement and Particular "Hetero-Images" of a Writer}

\begin{abstract}
At the end of the 1960s and in the beginning of the 1970s the South African poet Breyten Breytenbach had poetry and drawings published in the leading literary magazine Raster. The editor in charge at the time, H.C. ten Berge, gave the experimental writer and socially engaged Sestiger (the literary modernizing movement in South Africa in the sixties) pride of place in the line-ups of the Dutch modernist periodical. In the seventies, Ten Berge contributed to Vingermaan (1980), a collection of poems by Dutch writers (Lucebert, Kopland, Kouwenaar, Schierbeek) in support of the anti-apartheid activist. From 1975 Breytenbach was imprisoned in South Africa for political reasons. He served seven years of a nine year sentence. At that time, in the eighties, the Netherlands organized a cultural and economical boycott against the racist regime in Pretoria. Later on, Ten Berge
\end{abstract}


presented his own poems dedicated to Breytenbach in his book of poetry Nieuwe gedichten (1981) and in the collection Materia prima: Gedichten 1963-1993 (1993). Before and during the imprisonment of Breytenbach Ten Berge played an important role in the introduction of the writer in the Low Countries. From a cultural-sociological point of view Breytenbach's presence in the Dutch language area can be described, in the terminology of Françoise Lionnet and Shu-mei Shih and later on used by Louise Viljoen, as a transnational lateral movement in his writing career. This paper deals with the cultural transmission of an important political and experimental author in the literary system of Afrikaans and English in South Africa into the Dutch system. From a bibliographical viewpoint this paper affords special attention to the publication of Breytenbach's volume of poetry in Skryt: Om 'n sinkende skip blou te verf ([1972] 1976), Vingermaan (1980) and Nieuwe gedichten ([1981] 1987). Ten Berge played an important role in the introduction of Breytenbach to the Low Countries in the way he presented the author's political and aesthetic ideas to a Dutch-speaking audience.

Keywords: literary transculturalism; Dutch poetry; Afrikaans poetry; literary engagement; imagology; minor transnationalism

\section{Situationele context ${ }^{*}$}

Vingermaan is een coproductie van uitgeverij Meulenhoff en Galerie Espace (Amsterdam) en stond onder de redactie van Eva Bendien en Rutger Noordhoek Hegt. ${ }^{1}$ De bundel verscheen tijdens de gevangenisjaren (1975-1982) van de ZuidAfrikaanse antiapartheidsactivist Breyten Breytenbach $\left({ }^{*} 1939\right)$ op het moment dat de Nederlandse regering een culturele boycot voerde tegen het apartheidsregime. In de verantwoording berichten de samenstellers over de arrestatie, veroordeling en "tronkjare" van Breytenbach. Begin 1976 zijn potloodtekeningen alsook "berichten en brieven" van de Zuid-Afrikaanse dissident door een cipier buiten gesmokkeld en overhandigd aan de geheime politie (Bendien en Noordhoek Hegt 1980: z.p.). Nadat tijdens een nieuwe rechtszaak is aangetoond dat de bewaker het vertrouwen van de gedetineerde heeft geschonden en Breytenbach van de isolatiecel in Pretoria is overgebracht naar een gevangenis in de buurt van Kaapstad, zijn de persoonlijke brieven aan zijn echtgenote Yolande, het grafische werk en de literaire teksten overhandigd aan de familie. De verantwoording in Vingermaan maakt voorts duidelijk dat een ruime keuze is gepresenteerd uit de gevangenistekeningen en dat het boek diende ter ondersteuning van de

\footnotetext{
* De pre-paper is gepresenteerd op Cross-Over 2015 “Regionaal, (trans)nationaal, globaal. Definities en methodologieën, grenzen en gemeenschappelijke ruimtes, schrijvers en erfgoed," Adam Mickiewicz Universiteit, Poznań, 27-28 februari 2015.

${ }^{1}$ In de handelseditie van Ena Jansens proefschrift is een foto afgedrukt die door de auteur is genomen van Hans Ester en Adriaan van Dis tijdens de tentoonstelling van Breytenbachs tekeningen in Galerie Espace (1998: 77).
} 
gevangengezette politieke activist: "Deze uitgave verschijnt in het zesde jaar van Breyten Breytenbachs gevangenschap, tegelijk met een expositie van de gevangenistekeningen bij Galerie Espace te Amsterdam" (Bendien en Noordhoek Hegt 1980: z.p.). Naast tweeëndertig tekeningen omvat Vingermaan: Tekeningen uit Pretoria gedichten van H.C. ten Berge, Rutger Kopland, Gerrit Kouwenaar, Lucebert en Bert Schierbeek. ${ }^{2}$ Met name Ten Berge heeft de meest uitgebreide inzending geleverd. De bevindingen betreffende de in de gelegenheidsuitgave opgenomen poëzie van Kopland (T'Sjoen 2014a) en Lucebert (T'Sjoen 2015b) verduidelijken dat de dichters om evidente redenen en gezien de maatschappelijke opzet van de onderneming een ideologie-referentiële lezing van Breytenbachs werk hebben ondernomen. Op die manier sluit de poëzie zonder meer aan bij de opzet van de bundel. De verzamelde gedichten dienden ter ondersteuning van de gevangengenomen collega-schrijver en als proteststem tegen het gewelddadige apartheidssysteem van Zuid-Afrika. Ironisch is, althans volgens Breytenbach zelf in een recent gesprek, dat hij tot voor kort geen weet zou hebben van de artistieke steunbetuiging die in Nederland is ondernomen. ${ }^{3}$

De onderzoeksfocus van deze descriptieve bijdrage is het creatieve aandeel van Ten Berge in de Nederlandse boycot tegen de apartheid en de wijze waarop de schrijver en vertaler uitspraken heeft gedaan over Breytenbachs oeuvre en maatschappelijke positie. ${ }^{4}$ Ten Berge bundelde de gedichten van Vingermaan in Nieuwe gedichten (1981) en hij gaf op die manier de reeks en Breyten Breytenbach een plaats in het scheppende oeuvre.

\section{Transnationale schrijversbewegingen}

Schrijvers en teksten circuleren en functioneren niet uitsluitend in het taalgebied waar initieel de productie, distributie en receptie van het literaire werk plaatsvinden. Ze overschrijden in vele gevallen de grenzen van het eigen taalgebied of van het nationale circuit waartoe hun literatuur wordt gerekend. Dat gebeurt door middel van vertalingen, optredens op internationale festivals, interviews

\footnotetext{
${ }^{2}$ Koplands gedicht is eerder gebundeld in Al die mooie beloften (1978: 26). Kouwenaars reeks met vier gedichten in Vingermaan, die aanvangt met de apostrof "Voor Breyten," is met de afdelingstitel "brief in een fles voor breyten breytenbach" opgenomen in Het blindst van de vlek (1982: 37-40). Later heeft de schrijver de gedichten nog eens gepresenteerd in de zelfbloemlezing Helder maar grijzer: Gedichten 1978-1996 (2002: 41-44). In Kouwenaars auteursedities Een eter in het najaar (1991) en Vallende stilte (2008) ontbreekt de reeks. In zoverre ik het kon nagaan, heeft Bert Schierbeek de drie gedichten voor Breytenbach niet gebundeld.

${ }^{3}$ Een van de peer reviewers wijst erop dat ter gelegenheid van Breytenbachs vrijlating in 1982 publieke evenementen op het getouw zijn gezet in Nederland (onder meer georganiseerd door Hans ten Berge). De bewering van de auteur moet wellicht worden genuanceerd.

${ }^{4}$ De beeldvorming van Breytenbach in de Nederlandse literatuur is vanuit een breder (bourdieuiaans of veldtheoretisch) perspectief bestudeerd door Annemiek Recourt (2008).
} 
in anderstalige media (televisie, radio, kranten en tijdschriften, internetblogs en andere digitale media), interculturele netwerken, receptieteksten en kritische repertoires van anderstalige schrijvers en literatuurbeschouwers. Comparatief cultuursociologisch onderzoek naar literaire dialogen die de landsgrenzen en taalgebieden overschrijden en dus naar internationale trajecten van literatuur wordt onder de algemene noemer van het transnationalisme of de wereldliteratuur bestudeerd (Casanova 1999; Damrosch 2003).

Voor de theoretische en methodologische uitgangspunten in dit artikel baseer ik me op inzichten die elders voor soortgelijke gevalstudies zijn gebruikt (T'Sjoen 2015a, 2015b).

Transnationalisme of transculturaliteit als aanduiding van "die proses van globalisering" (Viljoen 2014: 5) is niet altijd een adequaat want te generaliserend instrument voor de beschrijving van particuliere schrijversloopbanen in een globaal perspectief. In deze bijdrage staat het concept van het "minor transnationalism" (Lionnet en Shih 2005) centraal. Zoals Viljoen (2014: 21) betoogt in haar "eerste verkenning [van] slegs die breë buitelyne van die ondersoeksveld" kunnen in de hedendaagse Afrikaanse literatuur ten opzichte van het Engels en het Nederlands verticale respectievelijk laterale bewegingen worden onderscheiden. $\mathrm{Zij}$ beschrijft meer bepaald de transnationale verschuivingen van de canonieke Afrikaanstalige (Zuid-Afrikaanse) schrijvers Breyten Breytenbach, André Brink, Etienne van Heerden, Antjie Krog en Marlene van Niekerk naar het Nederlandse taalgebied en daarbuiten in de Europese ruimte. ${ }^{5}$ Omgekeerd kunnen ook Nederlandstalige schrijvers onder wie Herman de Coninck, Luuk Gruwez, Gerrit Komrij, Rutger Kopland, Tom Lanoye, Harry Mulisch, Leonard Nolens, David van Reybrouck, Miriam Van hee, Willem van Toorn en Tommy Wieringa door bemiddeling van vertalers als Zandra Bezuidenhout, Heilna du Plooy, Daniel Hugo, Antjie Krog en Hennie van Coller tot het literaire systeem van het Afrikaans in Zuid-Afrika worden gerekend (Malan 2014). ${ }^{6}$

Er is vanzelfsprekend niet steeds, méér niet dan wel, sprake van een toetreding tot de mondiale literaire ruimte of dus een beweging in de richting van het Engelse taalgebied dat vandaag de metropool is van de wereldliteratuur. De verticale ontwikkeling draagt er toe bij dat het werk, oorspronkelijk tot stand gekomen in een kleine of middelgrote taal en in een veeleer perifere culturele context ten opzichte van het epicentrum, door bemiddeling van vertaling in het Engels - de contemporaine lingua franca van de internationale literaire wereld - wordt

\footnotetext{
${ }^{5}$ Aan de toetreding en de literaire positie van Elisabeth Eybers in Nederland is al jaren geleden een belangwekkende studie gewijd (Jansen 1998).

${ }^{6}$ De aanwezigheid van de literaire productie van Nederlandstalige auteurs in Zuid-Afrika is het onderwerp van een boek dat Ronel Foster en ik, met de steun van de Vereniging voor Internationale Neerlandistiek, voorbereiden in de reeks Lage Landen Studies (Academia Press, Gent, 2015). Zie: http:/ / nederl.blogspot.be/2015/02/call-for-papers-nederlandse-literatuur.html (5 februari 2015).
} 
opgenomen in wat de Franse cultuursocioloog Pascale Casanova de "République mondiale des lettres" (1999) noemt. Anders geformuleerd: "We realized [...] that our battles are always framed vertically, and we forget to look sideways to lateral networks that are not readily apparent" (Lionnet en Shih 2005: 1). Toetreden tot de Anglo-Amerikaanse publieke ruimte is vandaag een conditio sine qua non om als schrijver een internationale statuur te verkrijgen. Een verticale beweging is volgens Viljoen (2014: 6), in de lijn van Lionnet en Shih, een verschuiving van "'n marginale letterkunde" naar een mondiale en "'n Europese sentrum," een "laterale beweging" vindt plaats "tussen 'n marginale letterkunde en 'n letterkunde wat deel vorm van die Europese sentrum, maar nie noodwendig 'n sentrale rol daarin beklee nie." In dat laatste geval kunnen bewegingen tussen de "marginale taal" Afrikaans en het Nederlands dat in Europees perspectief een middelgrote taal is, worden geanalyseerd. Het onderzoek waar deze paper deel van uitmaakt betreft de aanwezigheid van Afrikaanse schrijvers in het Nederlands, met volgens recente cijfers van de Nederlandse Taalunie 23 miljoen moedertaalsprekers, dat overwegend deel uitmaakt van het Europese centrum maar niet behoort tot "die magtige metropolitaanse sentrums van die wêreld nie" (Viljoen 2014: 5). De literaire ruimte in Nederland is in sommige gevallen ook een cruciale transitzone naar andere Europese literaturen.

De zogeheten zijdelingse bewegingen van Zuid-Afrikaanse auteurs in Nederland en België documenteren hun "literêre status in die transnationale domein" (Viljoen 2014: 6). Hoewel minder prominent zijn ook andere dan canonieke Afrikaanse schrijvers present in de Lage Landen. In een ander artikel worden de ontwikkelingen in de schrijversloopbaan van Gert Vlok Nel en Charl-Pierre Naudé beschreven in de Nederlandse en Vlaamse literaire systemen (T'Sjoen 2015b).

\section{Een transculturele literatuurgeschiedenis}

De bemiddelende functie van vertalers (Van Coller en Odendaal 2007), schrijvers en critici, bloemlezers, redacteuren van uitgeverijen en andere culturele actoren voor de presentie en de receptie van buitenlandse literatuur is voor de Nederlandse literatuur nauwelijks bestudeerd. In de literatuurgeschiedschrijving is tot vandaag weinig aandacht besteed aan de receptie van anderstalige literaturen en evenmin aan de betekenis van teksten, auteurs en literaire debatten in het buitenland die het vertoog over literatuur in Nederland en Vlaanderen hebben gestuurd of die daarin een rol spelen. De verstrengeling van en de interacties tussen literaturen in verschillende talen vergen een uitvoerig onderzoek. Een literair veld wordt immers door een dynamiek van autochtone en allochtone ontwikkelingen gedetermineerd (Andringa, Levie en Sanders 2006: 197-198). Buitenlandse 
literatuur is aanwezig in vertalingen of als referentiepunt in literaire debatten, in de beschouwerspraktijk van recensenten en in het strategische repertoire van schrijvers: "de presentie van buitenlandse literatuur [heeft] het nationale literaire veld in belangrijke mate [...] gekleurd" (ibid.: 199). Teksten van Zuid-Afrikaanse (Afrikaans- en Engelstalige) auteurs functioneren in Nederland en Vlaanderen door bemiddeling van vertalers onder wie Riet de Jong-Goossens, Adriaan van Dis, Robert Dorsman, Krijn Peter Hesselink, Maarten Polman, Alfred Schaffer, Laurens Vancrevel, Jaap van der Haar en Rob van der Veer. Vertalingen fungeren bij uitstek maar niet uitsluitend als bemiddelaars tussen binnen- en buitenlandse circuits. Aan de betrokkenheid bij de interculturele transmissie van literatuur wordt in de literatuurgeschiedschrijving, zoals gezegd, weinig belang besteed. De keuze voor een "internationaal literair-historisch onderzoeksperspectief" (ibid.: 199) mag evident zijn maar wordt in het onderzoek tot op heden niet gemaakt. Belangrijke vragen betreffen de inbedding van Nederlandse literatuur in een internationaal kader, de interacties met buitenlandse literatuur, receptiepatronen van anderstalige literatuur in Nederland en Vlaanderen en de impact van gerecipieerde buitenlandse romans en poëzie op het literaire systeem (ibid.: 199).

Receptiestudie is een wijdvertakte discipline die om voor de hand liggende redenen uitgaat van een heuristisch-bibliografische onderzoeksvraag. De empirische studie van tijdschriften, zoals rubrieken over/met buitenlandse literatuur (in vertaling), culturele krantenbijlagen met gespecialiseerde katernen over anderstalige literatuur, digitale media en uitgeversfondsen die al dan niet in reeksverband buitenlandse teksten aanbieden, interviews met en publicaties van buitenlandse schrijvers et cetera, levert de basis voor de analyse van receptiepatronen. Dit onderzoek laat zien op welke wijze "de internationale dynamiek van de Nederlandse literatuur" verloopt. Tot de literair-institutionele context behoren zowel actoren, onder wie schrijvers, critici en vertalers, als instanties (letterenfondsen, uitgeverijen, periodieken). Ook voor de ontwikkeling van poëticale opvattingen of de wijze waarop een schrijver zich positioneert in een nationaal circuit of een eigen schrijfpraktijk legitimeert, spelen buitenlandse uitgevers, vertalers, schrijvers en teksten een niet onbelangrijke en in sommige gevallen zelfs een cruciale rol. Voor de specifieke casus die ik aan het einde van deze paper presenteer, is dat het geval. Deze naamsvermeldingen of in de terminologie van Karl Erik Rosengren 'mentions' kunnen een strategisch belang hebben en bijvoorbeeld op poëticale affiniteit wijzen. Het betekent dat schrijvers zich "op bepaalde werken als normatief referentiekader [...] beroepen." Naast de kritische receptie is er natuurlijk ook de scheppende receptie: werken kunnen "in een creatieve transformatie tot referentiepunt [...] worden." In dat geval betreft het "de intertextuele en transmediale verwerking in nieuw werk" van buitenlandse teksten (Andringa, Levie en Sanders 2006: 205). 
Vanuit documentair oogpunt ga ik de wijze na waarop Zuid-Afrikaanse schrijvers aanwezig zijn in een middelgrote Europese taal. In dat opzicht sluit ook deze bijdrage aan bij eerder ondernomen onderzoek naar de toetreding van Zuid-Afrikanen in de Nederlandse literatuur ( $T$ 'Sjoen 2014a,b,c; Viljoen 2014) en de intermediërende rol van vertalers en critici in de transnationale dialoog. Deze verkennende literair-documentaire onderzoeksbevindingen leggen de basis voor een breder opgezette receptiegeschiedenis en een poëticale en institutionele beschrijving van de laterale bewegingen tussen Afrikaanstalige schrijvers en het Nederlandse taalgebied.

Dit is hoofsaaklik die beweging van Afrikaans na die relatief klein taal Nederlands wat wel aansienlijke kulturele kapitaal verteenwoordig en in talle opsigte die eienskappe van 'n metropolitaanse literêre kultuur verteenwoordig. [...] Nederland en die Nederlandse literêre toneel bied [...]'n ruimte vir Afrikaanse skrywers maar dit is onwaarskynlik dat dit 'n deurslaggewende rol speel in hulle verdere deurgang tot die transnasionale ruimte. (Viljoen 2014: 21)

\section{Imagologisch onderzoek}

Deze bijdrage presenteert daarnaast imagologische onderzoeksbevindingen met betrekking tot Breyten Breytenbachs poëzie in het Nederlandse taalgebied. Het onderzoeksperspectief, zoals ingezet voor deze paper, ligt in de lijn van Wilfred Jonckheeres panoramische overzicht van beelden van Zuid-Afrika in de Nederlandse literatuur. Jonckheere beroept zich voor de imagologische studie voornamelijk op inzichten van de comparatist Hugo Dyserinck.

Belangrijk was dat Dyserinck [vaststelde] dat veel teksten over andere landen en vooral literaturen 'ein artifizielles Bild' [...] presenteerden of dat onderzoekers van andere culturen een 'image de leurs désirs' [...] schiepen. Dyserinck achtte het een belangrijke taak van de literatuurwetenschap deze 'illusies' over andere literaturen en culturen op te sporen en de stereotypen aan de kaak te stellen. (Jonckheere 1999: 12)

In de vergelijkende literatuurwetenschap manifesteert de imagologie zich de voorbije decennia als een onderzoek naar beeldvorming en transculturele representatie, of "als een interculturele confrontatie, waarbij een land het zelfbeeld toetst aan het beeld dat het van een ander land heeft" (Jonckheere 1999: 12). In Imagology: The Cultural Construction and Literary Representation of National Characters wordt het concept "image" gedefinieerd en voorgesteld als de constructie van een silhouet: "[ $[$ ]he nationality represented [...] is silhouetted in the perspectival context of the representing text or discourse" (Beller en Leerssen 2007: xiii-xiv). 
Imagology is not a form of sociology; it aims to understand a discourse rather than a society. Literary works unambiguously demonstrate that national characterizations are commonplace and hearsay rather than empirical observation or statements of fact. Our sources are subjective and rhetorically schematized. (Beller en Leerssen 2007: xiii)

Afhankelijk van culturele, ideologische, etnische en filosofische achtergronden beschouwen wij 'de ander' (een andere cultuur, een andere natie) als "heteroimages" en indien we zelf participeren in die cultuur of natie is er sprake van "self-images" of "auto-images." De studie van beeldconstructies gaat dus over discursieve stereotiepen, ook wel "imagotypes" (Leerssen 2007: 343), en specifieke vormen van intertekstualiteit: "Ethnotypes (i.e., stereotypical characterizations attributed to ethnicities or nationalities, national images and commonplaces) take shape in a discursive and rhetorical environment; they are representative of literary and discursive conventions, not of social realities" (Beller en Leerssen 2007: xiv).

De these die hier vooropstaat, is dat niet alleen 'andere' culturen en volkeren deel uitmaken van beeldonderzoek in de brede zin van het woord maar dat ook "gelegenheidspoëzie, populaire (historische) romans, jeugdromans, reisverhalen, geëngageerde poëzie" (Jonckheere 1999: 16) het voorwerp zijn van beeldconstructies of (re)presentatiewijzen en dus "een sterke beeldvormende werking" hebben. Indien de bronteksten deel uitmaken van een ander literair systeem, in dit geval de literatuur van het Afrikaans, presenteert de Nederlandse actor (in voorliggend geval Ten Berge) voor het leespubliek in de Lage Landen een "hetero-image." Het betreft dan een mentale of discursieve representatie van een anderstalige schrijver in Nederland. Indien we een "hetero-image" opvatten als "the referring to a characterological reputation current within and shared by a group, the latter to the opinion that others have about a group's purported character" (Leerssen 2007: 342-343), kan het concept natuurlijk specifieker en dus actor-gerelateerd worden ingezet. In beschouwingen over buitenlandse literatuur, het gebruik van interteksten, verwijzingen naar een particuliere geschiedenis wordt een beeld tot stand gebracht van een andere cultuur (een schrijver). Ook schrijvers ontwikkelen immers hun idiosyncratische beelden van de ander. Imagologisch onderzoek gaat over discursieve representaties: hoe beelden van andere volkeren en culturen via teksten zoals reisliteratuur, dagboeknotities, poëzie en verhalend proza worden geconstrueerd en verspreid.

Zo heeft Gerrit Komrij, de Nederlandse canoniserende bloemlezer en apologeet van de Afrikaanstalige poëzie in het Nederlandse taalgebied, een beeld tot stand gebracht van Breytenbachs poëzie voor een Nederlands publiek. Hij doet dat door een tekstselectie aan te bieden, in dit geval zijn keuze van in totaal tien gedichten van Breytenbach. Interessant is te achterhalen welke representatietechnieken 
en -strategieën bij de tekstselectie en dus de beeldvorming een rol hebben gespeeld (T'Sjoen 2015b). De veronderstelling is dat de Nederlandse lezer op het einde van het millennium een beeld van de vroege persona poetica Breytenbach gepresenteerd kreeg dat niet vrij is van "clichés en stereotiepen" (Jonckheere 1999: 12). Mijn bevindingen heb ik verbonden met een soortgelijke lezing van de representatie van Breytenbach in een gedichtencyclus die Lucebert publiceerde in Vingermaan. In deze casus gaat het dus niet over "images" van andere naties, culturen of volkeren maar over de beeldvorming van een anderstalige literatuur, in casu een canonieke schrijver, in Nederland door middel van een tijdschrift (Raster) én het scheppende en beschouwende werk van een literaire actor (H.C. ten Berge).

\section{Nieuwe onderzoeksvragen}

[Françoise Lionnets en Shu-mei Shihs] definisie [van minor transnationalism] gee erkenning aan die feit dat transnationalisme deel uitmaak van die proses van globalisering, maar ook dat dit op ander maniere en meer verspreid kan voorkom as wat ['n] beeld van sentripetale en sentrifugale kragte suggereer. As sodanig is die transnasionale nie gebonde aan die binêre opposisie tussen die lokale en die globale nie, maar kan dit voorkom in 'n verskeidenheid van lokale, nasionale of globale ruimtes en versprei wees oor verskillende ruimtes en tydperke. (Viljoen 2014: 5; vgl. Lionnet en Shih 2005: 5)

Globalisering en transnationalisme zijn containerbegrippen die vele variëteiten en strategieën insluiten. Wat we in elk geval voor ogen moeten houden, is dat "[m]inority cultures are part of our transnational moment" (Lionnet en Shih 2005: 7). Waar bijvoorbeeld voor Gert Vlok Nel geldt dat zijn poëzie deel uitmaakt van een laterale transnationale beweging, nagenoeg uitsluitend gericht op het Nederlandse literaire (poly)systeem, kan voor Charl-Pierre Naudé worden gesteld dat hij de toegangspoort naar een veeleer geglobaliseerde en dus transnationale ruimte zelf forceert - onder andere via Nederland en Vlaanderen in Duitsland (meer bepaald in Berlijn waar hij in opdracht van de Deutscher Akademischer Austauchdienst tot maart 2015 een jaar lang writer in residence was) - en zijn schrijversloopbaan door de Engelstalige presentie (en vooralsnog beperkte receptie) een verticale beweging ondergaat. Het is duidelijk dat Naudé als schrijver veel bewuster werkt aan een meer internationale statuur.

Voor de volgende gevalstudie wordt een eclectisch samengestelde toolkit gebruikt die concepten van het transnationaliteits- en imagologische onderzoek met elkaar combineert en productief kan zijn om Ten Berges beeldconstructies 
van Breytenbach te duiden als biografische persoon en als kunstenaar in de context van het periodiek Raster. ${ }^{7}$

\section{6. "Een droomgezicht, Breyten, de prent." H.C. ten Berges beeld- vorming van Breyten Breytenbach}

Voor de gevalstudie over de beeldconstructies van Breytenbachs werk en persoonlijkheid door H.C. ten Berge (1938) verwijs ik uitsluitend naar de eerste jaargangen van het avant-gardeperiodiek Raster en naar de dichtbundel Nieuwe gedichten (1981).

\subsection{Breytenbach in de jaren zestig}

Ten Berge voerde tussen 1967 en 1972 de eenmansredactie van het Nederlandse experimentele tijdschrift Raster. In de eerste reeks zijn tussen 1969 en 1972 naast enkele tekeningen in totaal negenentwintig gedichten en een prozatekst van Breytenbach gepubliceerd (Goedegebuure 1993: 219). Ook later, vanaf de tweede reeks (1977-2009), heeft Breytenbach met teksten bijgedragen tot Raster. Raster markeert in het literaire landschap van de jaren zestig een antimimetisch en modernistisch-intellectualistisch discours dat als een antidotum voor het salonfähige Hollandse huiskamerrealisme kan worden gezien. In jaren van toenemende democratisering en maatschappelijke contestatie bepaalde een nieuwrealistisch paradigma het artistieke klimaat in Europa en de Verenigde Staten. Tegenover een mimetische tendens in de eigentijdse literatuur, met onder meer de defictionalisering van de reportage- of documentaire roman (Harry Mulisch, Enno Develing) en het gebruik van de ready-mades in neo-dadaïstische poëzie (Armando, Hans Verhagen, J. Bernlef, K. Schippers), manifesteerde Raster zich als een blad dat volgens Ten Berges programmatische tekst gebaseerd is op het concept van de "logopoeia." Volgens dat begrip is het intellect en niet de emotie de katalysator van het kunstwerk (Musschoot 2009: 623). Het tijdschrift functioneerde als een experimenteel labo waarin termen als 'ander proza' (Sybren Polet) en de dichter als 'constructeur' zijn gemunt én onderzoek is ondernomen naar de verhouding tussen taal en werkelijkheid. ${ }^{8}$ In het perspectief van de belangstelling

\footnotetext{
${ }^{7}$ De theoretische omkadering van deze bijdrage ligt ook ten grondslag aan de gevalstudies die zijn ondernomen met betrekking tot de aanwezigheid van Charl-Pierre Naudé en Gert Vlok Nel in de Lage Landen (T'Sjoen 2015a) en Komrij's lezing van Breytenbachs poëzie (T'Sjoen 2015b). Voorliggende casus maakt deel uit van het onderzoek naar transculturele bewegingen in schrijversloopbanen van Zuid-Afrikaanse (Afrikaanstalige) actoren in het Nederlandse taalgebied.

${ }^{8}$ Naar eigen zeggen en post factum is de eerste reeks van Raster "een open podium" met een duidelijk "literair programma." Naar aanleiding van een uitspraak betreffende de marxistisch-leninistische grondslag van het vroege Raster merkt H.C. ten Berge op dat alleen enkele bijdragen van Jacq Vogelaar vanuit een geprononceerd ideologisch standpunt zijn geschreven. Hij omschrijft zijn eigen rol als
} 
voor "littérature engagée," voor literatuurtheorie en vormdiscussies in verschillende kunstdisciplines, alsook gelet op de transculturele focus van de redactie is het niet zo opmerkelijk dat naast veel andere internationale schrijvers ook de experimentele dichter, prozaschrijver en politieke dissident Breytenbach tot het kritische en strategische repertoire van de Raster-equipe behoorde. Later heeft Ten Berge de belangstelling voor Breytenbach en Brink als volgt toegelicht:

Gevoed door nieuwsgierigheid wilde Raster binnen- en buitengaats opereren en zich informeren over de stand van zaken binnen en buiten onze taalgrenzen. [...] Tot mijn genoegen bleek het dus mogelijk stimulerende contacten te onderhouden met schrijvers en essayisten uit verscheidene landen. Ik denk aan de scheppende bijdragen van Breyten Breytenbach en André Brink uit Zuid-Afrika, Kenneth White en Nathaniel Tarn uit Engeland, Gary Snyder en Jerome Rothenberg uit de Verenigde Staten, Edoardo Sanguineti uit Italië en anderen, die ongenoemd moeten blijven. De medewerking van deze auteurs had voor mij een bijzondere betekenis omdat ze iets opleverde dat in die periode werkelijk nieuw en opwindend was: de gewaarwording van een gemeenschappelijke grondslag die rechtstreeks te maken had met [een] levenshouding ['een houding in de tijd']. (Ten Berge 1996: 136-137)

De Nederlandse aandacht voor het werk van de Afrikaansschrijvende balling in Parijs is aanvankelijk niet gerelateerd aan de strijd die de schrijver en schilder op dat moment al jarenlang voerde tegen het op racisme en segregatie gefundeerde politieke systeem van zijn vaderland. Goedegebuure (1993: 219) heeft erop gewezen dat de idiosyncratische schriftuur van Breytenbach en de esthetische opvatting dat het Afrikaans "een vruchtbaar poëtisch medium" is oorspronkelijk de receptie hebben bepaald. In vervolgonderzoek wordt vanuit literair-institutioneel en poëticaal oogpunt de Raster-productie van Breytenbach bestudeerd. We proberen na te gaan hoe de persoonlijke contacten tussen Ten Berge en de ZuidAfrikaan medio jaren zestig zijn verlopen en welke tekstkeuze door Ten Berge is gemaakt. ${ }^{9}$

De aandacht van H.C. ten Berge voor Breytenbachs literaire productie in ballingschap, sinds het door surrealisme en Zenboeddhisme bepaalde poëziedebuut Die ysterkoei moet sweet (1964) en de experimentele verhalenbundel Katastrofes (1964), leidde in 1976 tot de vermeerderde tweede uitgave van Skryt: Om ' $n$ sinkende skip blou te verf in het fonds van Meulenhoff. Het boek is opgenomen

die van een "libertaire anarchist (met vreedzame bedoelingen)." Verder stelt hij met betrekking tot deze gevalstudie: "Breyten paste daar zeer goed in. Hij zegde onmiddellijk bijdragen toe, toen ik hem opbelde vanuit NL. Spoedig daarna hebben we elkaar ontmoet, zowel in Amsterdam als Parijs, en werd de vriendschap bezegeld!". E-mail van H.C. ten Berge aan Yves T'Sjoen, dd. 17 februari 2015.

${ }^{9}$ In samenwerking met Camille Bourgeus is momenteel een artikel in voorbereiding met aandacht voor de Raster-bijdragen van Breytenbach (1969-1972) vanuit een institutioneel en poëticaal perspectief. 
in de Poetry International Serie (in samenwerking met de Rotterdamse Kunststichting) met in een afzonderlijk katern de Nederlandse vertaling door Adriaan van Dis (Skryt: Om een zinkend schip blauw te verven). ${ }^{10}$ Ten Berge leidde de bundel uit en wees in het kapittel "Van Skryt tot strijd" op het belang van het politieke militantisme van Breytenbach. ${ }^{11}$ Het "nabericht over het werk van Breyten Breytenbach" is gedateerd maart 1972 en was al eerder opgenomen in de eerste druk van Skryt. In het "Naschrift 1975" wijst Ten Berge de lezer op "enkele gebeurtenissen" die zich in tussentijd hebben "voorgedaan die de trieste grimmigheid van een en ander onderstrepen":

In het tweede deel van het nabericht heb ik geen wijzigingen willen aanbrengen. De beschreven situatie geeft de stand van zaken omstreeks 1972 weer. [...] Ten slotte moet herinnerd worden aan het lot van Breytenbach zelf die niet alleen Skryt en een gedeelte van zijn jongste werk in ZuidAfrika verboden zag worden, maar nu ook in persoon de gevolgen van zijn aktiviteiten-ter-plaatse moet dragen. (Ten Berge 1976: 69)

Goedegebuure spreekt met betrekking tot de toelichting over een kentering in de kritische ontvangst en benadrukt het politiek-ideologische (en dus niet langer het esthetische) referentiekader waarin Breytenbachs werk voortaan betekenis is gegeven. Toen Breytenbach in 1975 zonder visum naar Zuid-Afrika reisde, is hij gearresteerd en op beschuldiging van terroristische activiteiten veroordeeld tot negen jaar gevangenisstraf. Dit biografische gegeven en het feit dat de ZuidAfrikaanse dissident als lid van Okhela (de blanke vleugel van het African National Congress) het verzet tegen de apartheid vanuit het buitenland organiseerde (Jonckheere 1999: 172), hebben in Nederland en Vlaanderen de politieke en referentiële lezing van het literaire werk aangescherpt ten nadele van de aandacht voor literariteit in Breytenbachs teksten (T'Sjoen 2014a: 65-66). Hoe vanzelfsprekend deze bijgestuurde lezing ook is in het licht van de politieke gebeurtenissen en het lot dat Breytenbach vanaf 1975 beschoren was, verdient de paradigmatische verschuiving in Ten Berges referentiekader nader onderzoek. Al in 1972, dus

\footnotetext{
${ }^{10}$ Eerst is de bundel aan breyten breytenbach (Bureau Poetry International en Rotterdamse Kunststichting) verschenen naar aanleiding van de vrijheidsberoving van de auteur. Schrijvers die net als de Zuid-Afrikaanse schrijver (Breytenbach vanaf 1971) deel uitmaakten van het gezelschap dat heeft opgetreden tijdens evenementen van Poetry International en bijdragen leverden voor de gelegenheidspublicatie zijn onder anderen J. Bernlef, C. Buddingh', Remco Campert, Gerrit Komrij, Sjoerd Kuyper, Eddy van Vliet en anderstalige dichters (Jonckheere 1999: 172). Verkeerdelijk rekent Jonckheere "M. Wauters" (de Aalstenaar Marcel Wauters) tot de buitenlandse in casu niet-Nederlandstalige dichters. Het verdient de nodige aandacht Adriaan van Dis' vertalingen van en toelichtingen bij het werk van Breytenbach nader te bestuderen.

${ }^{11}$ H.C. ten Berge maakte deel uit van de jury die Breytenbachs bundel Lotus bekroonde met de Lucy B. en C.W. van der Hoogtprijs (1972). H.C. ten Berge, K. Fens en H. Oosterhuis, “Rapport van de jury voor de Lucy B. en C.W. van der Hoogt-prijs 1972," in: Jaarboek van de Maatschappij der Nederlandse Letterkunde te Leiden. Met verslag van de toekenning en dankwoord van Breytenbach. Leiden: Brill, 1973, 303-308. Het juryverslag kan worden nagelezen: <http:/ / www.literatuurplein.nl/litprijseditie. jsp?litPrijsEditieId=593> (geraadpleegd op 14 februari 2015).
} 
nog voor de arrestatie en veroordeling, wees Ten Berge op de ethische dimensie van zijn belangstelling voor Breytenbachs artistieke werk. Mogelijk, zoals Goedegebuure (1993: 219) beweert, wilde hij op die manier de literaire en politieke persoonlijkheid Breytenbach bekend maken buiten de Raster-entourage. Na een esthetisch-thematische en algemeen culturele benadering van Skryt weidt Ten Berge (1976: 65) uit over "de politieke en revolutionaire noties in zijn werk": "Men zal het mij vergeven wanneer ik de ritmiese, estetiese en andere eigenschappen van Breytenbachs intiemere lyriek verder buiten beschouwing laat.")

\subsection{Breytenbach in de jaren tachtig}

"Intra muros" is de reekstitel van acht gedichten (of tekstfragmenten) die Ten Berge presenteerde in Vingermaan (1980), de compilatiebundel van Nederlandse schrijvers en galerijhouders voor de op dat moment vijf jaar opgesloten antiapartheidsmilitant. De reeks is opgedragen aan "yolande en de lotuseter." Yolande Hoang Lien (letterlijk: lotus) is de echtgenote van de auteur, "de lotuseter" verwijst naar de familienaam van de Française met Vietnamese roots alsook naar Breytenbachs dichtbundel Lotus (1970). Als gevolg van de Mixed Marriages Act van de blanke minderheidsregering in Pretoria kregen Breytenbach en zijn echtgenote niet de toelating naar Zuid-Afrika te reizen. Alleen in 1972 ontvingen zij uitzonderlijk een visum voor een bezoek van drie maanden. Sinds het begin van de jaren zestig verbleef Breytenbach in gedwongen ballingschap in Parijs (Francken en Renders 2005: 82).

In het voorjaar van 1981 zijn Ten Berges teksten gebundeld in Nieuwe gedichten (BBPoëzie). Zes jaar later verscheen een tweede druk in de reeks BB Poëzie-pocket met op het omslag een tekening van Lucebert en een nawoord van Maarten van Buuren. De tiende elegie in Texaanse gedichten (1983) is een heruitgave van een gedicht dat eerder is opgenomen in Nieuwe gedichten. In de verzamelbundel Materia prima: Gedichten 1963-1993 zijn zowel Nieuwe gedichten als Texaanse elegieën integraal overgenomen. De uitgaven van 1980 (Vingermaan) en 1981 (Nieuwe gedichten) vertonen één woordvariant: in het openingsgedicht is "papajas" vervangen door "pompoenen" (r.6). De bundel bevat twee annotaties bij de afdeling "Intra muros": “'Wellington toe met lang bene' en 'bordienghuis': toespelingen op Breyten's gedicht 'Ek sal sterf en na my vader gaan'” en "De citaten in 'Slechtzittend gedicht': psalm 83 (r.3) en psalm 10 (r.9)."

Nieuwe gedichten omvat vijf afdelingen: "De Hartlaubmeeuw," "Zeven tijdstippen," "Een schijn van werkelijkheid," "Tramontane" en "Intra muros." De eerste en de vijfde cyclus refereren onder meer expliciet aan de persona pratica Breytenbach en bevatten metaforen die in de poëzie van de Zuid-Afrikaanse schrijver voorkomen. De eerste geciteerde aantekening refereert aan een vadergedicht dat in ' $n$ Seisoen in die paradys (1977) is opgenomen. In de door Adriaan 
van Dis en Hans Ester verzorgde Nederlandse vertaling Een seizoen in het paradijs (1980) komt het gedicht voor op pagina's 201 en 202.

Maarten van Buurens nawoord in de tweede druk van Nieuwe gedichten biedt een tekstinterpretatie. De Nederlandse literatuurwetenschapper stelt dat literaire vrienden een cruciale rol vertolken in Ten Berges dichtwerk:

In de poëzie van Hans ten Berge komen figuren voor met wie de dichter zich op afstand identificeert. Die 'verre vrienden' vervullen soms de rol van gids. [...] Het zijn verwante geesten, broers bijna, die door Ten Berge met grote sympathie worden geportretteerd. Toch denk ik dat die vriendschap de werkelijke reden camoufleert waarom ze in zijn gedichten voorkomen; de vrienden zijn belangrijk omdat ze de spiegel vormen waarin de dichter zicht krijgt op zichzelf. (Van Buuren 1987: 61)

Met betrekking tot de paratekstuele vermelding van Breytenbach ("de lotuseter" in de opdracht bij "Intra muros") ${ }^{12}$ en vooral de prominente positie die de schrijver inneemt in Nieuwe gedichten merkt Van Buuren (1987: 61) nog op: "de Zuidafrikaanse [sic] dichter [vertegenwoordigt] kwaliteiten [...] die Ten Berge wezenlijk acht voor zijn eigen bestaan: een gevoel van permanente ontheemding [...], verzet tegen het vaderland en natuurlijk het dichten als middel om enerzijds afstand te nemen van het land van herkomst en anderzijds een nieuw, innerlijk landschap te ontwerpen waarin de dichter zijn bestemming vindt." Vervolgens bespreekt de auteur de openings- en slotafdeling, respectievelijk "De Hartlaubmeeuw" en "Intra muros," teneinde zich de retorische vraag te stellen:

Is dit geëngageerde poëzie? Zeker. Maar niet van het soort dat we daar gewoonlijk onder verstaan. Geen politieke leuzen dus, maar engagement van een veel breder strekking die ook de betrekkelijk rustige situatie in Nederland omvat. Dat verklaart waarom het vaderhuis-gedicht ['Ik zal sterven en naar mijn vader gaan, naar Wellington met lange benen' in Een seizoen in het paradijs] de dood van zijn eigen vader gedenkt en met een vergelijkbare revolte zijn eigen vaderland de rug toekeert [...]. Verder mogen we niet vergeten dat het engagement van de dichter een dichterlijk engagement is. De vraag waar 'Intra muros' op eindigt is dan ook hoe de dichter er in de meest benarde omstandigheden in slaagt de werkelijkheid in taal te ordenen. (Van Buuren 1987: 62-63)

Van Buurens lezing strookt niet met de bevinding van Goedegebuure, die zoals eerder aangestipt wees op Ten Berges gewijzigde (politieke) voorstelling van Breytenbachs werk in het nawoord van Skryt (1976 [1972]). Kort samengevat komt Van Buurens benadering erop neer dat Ten Berges beeldconstructie van Breytenbach in "Intra muros" ("de lotuseter"), en bij uitbreiding "De Hartlaubmeeuw"

${ }^{12}$ Het gedicht in de eerste afdeling "De Hartlaubmeeuw" wordt geflankeerd door de volgende sarcastisch getoonzette paratekst: "Aan B.B. die negen jaar in de nor opknapt." 
in Nieuwe gedichten ("Breyten" en "B.B."), van esthetische en idiosyncratische aard is. De reminiscenties en interteksten, zoals het vaderhuisgedicht en de specifieke beeldengrammatica van Breytenbach, functioneren voor Ten Berge als een spiegel. In de terminologie van Beller en Leerssen kunnen we stellen dat het "hetero-image" - de beeldvorming vanuit een andere cultuur - hier samenvalt met een "auto-image" (een toe-eigening of identificatie). Ten Berge herkent zich in Breytenbach als een ontheemde. Hij identificeert zich met de maatschappelijke uitzonderingspositie ("intra muros") die Breytenbach inneemt.

Het vergt nader onderzoek deze zogenaamde toe-eigeningen in een poëticaal perspectief te plaatsen. Het is bekend dat Ten Berge zich in zijn poëzie associeert met een middeleeuwse vagant, in Nieuwe gedichten (en elders) een 'tramontane' of nomadische dichter. De taalwerkelijkheid die hij in zijn teksten opbouwt, zijn volgens Van Buuren (1987: 65) innerlijke landschappen: “Landschappen spelen een grote rol in zijn gedichten. Het zijn barre, onherbergzame en onnederlandse gebieden zoals de poolkap of een woestijn of een hooggebergte, maar ze hebben allemaal gemeen dat ze op directe of indirecte manier het dichterschap weerspiegelen." Deze metatalige thematiek - poëzie over het dichten - kan inderdaad worden beschouwd als een verbindingsstreep tussen Breytenbach en Ten Berge. Opvallend is dat Van Buuren in zijn discours niet zozeer de politieke dimensie onder de aandacht brengt maar wel de op taal en dichterschap gerichte motieven. De vraag is vervolgens of Ten Berges visie op Breytenbach tussen Skryt (1976 [1972]) en Vingermaan (1980)/Nieuwe gedichten (1981) een spectaculaire herziening kreeg dan wel of de ethische respectievelijk esthetische zienswijzen vooral op het conto van Goedegebuure en Van Buuren moeten worden geschreven. In ieder geval presenteren beide secundaire beschouwingen (1987 resp. 1993) vanuit imagologisch perspectief afwijkende beeldconstructies van Ten Berges lezing van Breytenbachs literaire werk.

\section{Besluit}

Voor een ruimer en meer genuanceerd perspectief op deze imagologische en transnationale kwestie moeten vanzelfsprekend ook eigentijdse en latere (on)gepubliceerde teksten van Ten Berge over Breytenbach worden meegenomen, ${ }^{13}$

\footnotetext{
${ }^{13}$ Onder meer voor de hier betreffende periode: H.C. ten Berge, “Dichter zonder taal, schilder zonder ogen," in: De Gids 138(9) (1975), 565-576 en opgenomen in: Idem, Levenstekens $\mathcal{E}$ Doodssinjalen. Amsterdam: De Bezige Bij, 1980, 285-310 en "Niet bestelde brief aan een nomade," in: Tydskrif vir Letterkunde 46(2) (2009). Ter gelegenheid van Breytenbachs zeventigste verjaardag hernam Ten Berge een open brief "aan Breyten" die onder de titel " De grote race der zielen ten hemel.' Nog meer korrespondentie" is opgenomen in de titelnovelle van H.C. ten Berges De beren van Churchill. Amsterdam: De Bezige Bij, 1978, 70-78. Hieromtrent merkt de auteur op: “De tekst is opgenomen geweest in De Beren van Churchill (1977 of 1978), een prozaboek met een uitwaaierende reeks verhalen en observaties.
} 
eventueel persoonlijke brieven die de Nederlandse en Zuid-Afrikaanse schrijvers hebben gewisseld (Ten Berge 1996: 136) alsook interviews met Ten Berge over het werk van zijn Zuid-Afrikaanse collega. Het tekstencorpus is veelomvattender dan de hier geselecteerde verbindingsmomenten, met name Raster en respectievelijk Skryt en Nieuwe gedichten, die in de gevalstudie te berde zijn gebracht. Ook de poëticale ontwikkeling, het specifieke idioom, de beeldengrammatica en het lexicon van Ten Berges proza en poëzie met de antropologische belangstelling voor Eskimo's, Indianen, Azteken en andere 'natuurvolkeren,' met hun eigen cultuur, rituelen en mythen, verdienen nadere beschouwing. De wijze waarop Ten Berge in poeticis en in beschouwende teksten uiteenlopende beelden van Breytenbach heeft ontworpen, moet nog verder worden bekeken. ${ }^{14}$ Beide afdelingen in Nieuwe gedichten, met "Intra muros" dat in de gelegenheidspublicatie Vingermaan voor het eerst is gepresenteerd, reiken hiervoor het tekstmateriaal aan. Intussen onderschrijf ik de afsluitende opmerking van Maarten van Buuren over het ultieme streven van de persona poetica H.C. ten Berge. Omdat ze misschien wel de formulering is van het sterkste verbindingsteken tussen de Nederlandse schrijver en Breytenbach, méér dan welke intertekstuele relaties en expliciete (para)tekstuele notities ook: "De uiteindelijke consequentie waar de dichter zich voor gesteld ziet is dat hij ondergeschikt wordt gemaakt aan zijn

Ik verbleef in Canada in 1974/75, toen ik verbonden was aan het Museum van Volkenkunde in Ottawa (als niet-academicus: zoiets zou in Nederland ondenkbaar zijn geweest waar een positie tussen kunst en wetenschap per definitie wordt gewantrouwd!). Na terugkeer ontdekte ik dat Breyten onbereikbaar bleek. Latere contacten met zijn vrouw brachten verheldering, evenals berichten in de pers." E-mail van H.C. ten Berge aan Yves T'Sjoen, dd. 18 februari 2015. Naar aanleiding van een overzichtstentoonstelling met beeldende kunst van Breytenbach gaf Ten Berge een lezing over het literaire werk: "Omstreeks 2009 was er een grote overzichtstentoonstelling van Breytens beeldend werk in de stad Hengelo (Twente, Oost-NL). Laurens van Krevelen leidde die indrukwekkende expositie in, terwijl mij gevraagd was een lezing over het literaire werk te houden in de stadsbibliotheek. De tekst van die lezing stuur ik $u$ in een bijlage toe. Zoals u zult merken was Breyten (met zijn vrouw) daarbij aanwezig. Het publiek was niet vertrouwd met zijn werk, waardoor ik soms terug moest grijpen op eerder gemaakte opmerkingen. Toch maakte ik van de gelegenheid gebruik om te wijzen op de parallellen met de liefdespoëzie van Herman Gorter (een vergelijking tussen Lotus en de sensitieve verzen van Gorter uit 1890 lag voor de hand), zodat er ook iets werkelijk nieuws verteld kon worden." E-mail van H.C. ten Berge aan Yves T'Sjoen, dd. 17 februari 2015. Deze onuitgegeven tekst, getiteld "De grillige lijn. Een verkenning van Breyten Breytenbachs geschreven werk," verdient nadere beschouwing.

${ }^{14}$ Van Buuren wijst voor het gedicht "De Hartlaubmeeuw" op de "(fictieve?) foto" en de "dreiging [die] werkelijkheid [is] geworden: Breytenbach zit een langdurige gevangenisstraf uit en de foto die de dichter ons toont is dus een herinnering aan beter tijden." In zijn literair-anekdotische interpretatie van de reeks "Intra muros" benadrukt hij de "talloze toespelingen op de situatie in Zuid-Afrika: de brief die Ten Berge uit de gevangenis ontvangt, de satire op de Zuidafrikaner [sic] kerken die het apartheidsregime ondersteunen, de tekeningen die Breytenbach maakt van mensen in gevangenschap." Hij besluit: "[Het] beeld van een hels vaderhuis neemt Ten Berge [van Breytenbach] over en hij werkt het uit: in de rokerige kamers en kelders worden gevangenen verhoord, gemarteld en vermoord." Verder in de bijdrage geeft hij aan dat alle buiten-literaire of referentiële én intertekstuele verwijzingen deel uitmaken van Ten Berges ontwerp van een "'innerlijk landschap.'” (Van Buuren in Ten Berge 1987: 61-65) 
taal; dat hij als individu in die taal verdwijnt. Wat overblijft is een gebergte dat Ten Berge verzwolgen heeft" (Van Buuren in Ten Berge 1987: 65). ${ }^{15}$

Bibliografie

Andringa, E., S. Levie, en M. Sanders. 2006. “Het buitenland bekeken: Vijf internationale auteurs door Nederlandse ogen (1900-2000)." Eds E. Andringa, S. Levie, en M. Sanders. Nederlandse Letterkunde 11(3): 197-210.

Beller, M. 2007. "Stereotype." Imagology: The Cultural Construction and Literary Representation of National Characters. A Critical Survey. Eds M. Beller, en J. Leerssen. Amsterdam/ New York: Rodopi. 429-434.

Beller, M., en J. Leerssen. 2007. “Forword." Imagology: The Cultural Construction and Literary Representation of National Characters. A Critical Survey. Eds M. Beller, en J. Leerssen. Amsterdam/New York: Rodopi. xiii-xvi.

Bendien E., en Noordhoek Hegt, R. 1980. "Verantwoording." Vingermaan: Tekeningen uit Pretoria met bijdragen van H.C. ten Berge, Rutger Kopland, Gerrit Kouwenaar, Lucebert en Bert Schierbeek. B. Breytenbach. Amsterdam: Meulenhoff en Galerie Espace. Z.p.

Berge, H.C. ten. 1976 [1972]. "Een nabericht over het werk van Breyten Breytenbach." Skryt: Om 'n sinkende skip blou te verf. Verse en tekeninge. B. Breytenbach. Amsterdam: Meulenhoff/Poetry International. 61-72. 1978. De beren van Churchill. Amsterdam: De Bezige Bij. 1980. “Dichter zonder taal, schilder zonder ogen." Levenstekens \& Doodssinjalen. H.C. ten Berge. Amsterdam: De Bezige Bij. 285-310. . 1983. Texaanse elegieën. Amsterdam: De Bezige Bij. 1987 [1981]. Nieuwe gedichten. Amsterdam: De Bezige Bij. 1993. Materia prima: Gedichten 1963-1993. Amsterdam: Meulenhoff.

1996. "De eerste jaren van het tijdschrift Raster: Drie korte vragen en iets langere antwoorden." Vrouwen, jaloezie en andere ongemakken: Dagboekbladen, veldnotities 2. H.C. ten Berge. Amsterdam: Meulenhoff. 132-143.

Bergh, E. van den. 2003. "Breytenbach in Nederland." Cultuur en migratie in Nederland: Kunsten in beweging 1900-1980. Eds M. Meijer, en R. Buikema. Den Haag: Sdu uitgevers. 345-360.

Breytenbach, B. 1980. Vingermaan: Tekeningen uit Pretoria met bijdragen van H.C. ten Berge, Rutger Kopland, Gerrit Kouwenaar, Lucebert en Bert Schierbeek. Amsterdam: Meulenhoff en Galerie Espace.

Buuren, M. van. 1987. “Nawoord.” Nieuwe gedichten. H.C. ten Berge. Amsterdam: De Bezige Bij. 61-66.

Casanova, P. 1999. La République mondiale des lettres. Paris: Éditions du Seuil.

Coller, H.P. van, en B. Odendaal. 2007. “Antjie Krog's Role as Translator: A Case Study of Strategic Positioning in the Current South African Literary Poly-system." Current Writing 19(2): 94-121.

Damrosch, D. 2003. What is World Literature? Princeton: Princeton University Press.

\footnotetext{
${ }^{15}$ Met dank aan het Poëziecentrum (Gent) voor de logistieke ondersteuning en aan Breyten Breytenbach en H.C. ten Berge voor de mailcorrespondenties. Charl-Pierre Naudé las de Engeltalige abstract na. De peer reviewers zijn dank verschuldigd voor de waardevolle suggesties.
} 
Francken, E., en L. Renders. 2005. Skrywers in die strydperk: Krachtlijnen in de Zuid-Afrikaanse letterkunde. Amsterdam: Bert Bakker.

Galloway, F. 1990. Breyten Breytenbach as openbare figuur. Pretoria: HAUM-Literêr.

Goedegebuure, J. 1993. “'De weerklank wordt door de situatie bepaald.' Breyten Breytenbach in de spiegel van de Nederlandse kritiek." Literatuur 10(4): 217-222.

Jansen, E. 1998. Afstand \& verbintenis: Elisabeth Eybers in Amsterdam. Amsterdam: Amsterdam University Press.

Jonckheere, W. 1999. Van Mafeking tot Robbeneiland: Zuid-Afrika in de Nederlandse literatuur 1896-1996. Nijmegen: Vantilt.

Komrij, G. 1999. De Afrikaanse poëzie in 1000 en enige gedichten. Amsterdam: Bert Bakker.

Leerssen, J. 2007. “Image." Imagology: The Cultural Construction and Literary Representation of National Characters. A Critical Survey. Eds M. Beller, en J. Leerssen. Amsterdam/New York: Rodopi. 342-344.

Lionnet, F., en Shih, S. 2005. "Introduction. Thinking through the Minor, Transnationally." Minor transnationalism. Eds F. Lionnet, en S. Shih. Durham/London: Duke University Press.

Musschoot, A.M. 2009. “The Imagination Seizes Power, 1970-1980." A Literary History of the Low Countries. Ed T. Hermans. Rochester/New York: Camden House. 623-644.

Recourt, A. 2008. “Niet te véél aksent op het 'Zud-Afrikaanse' als-je-blieft: De materiële en symbolische productie van het oeuvre van Breyten Breytenbach in Nederland." Diss. Universiteit van Amsterdam.

T'Sjoen, Y. 2014a. "'Lang aktueel blijven.' Breyten Breytenbach in de poëzie van Rutger Kopland." Y. T'Sjoen. 'Zoals een grens op de kaart.' Nederlandse literatuur in vergelijkend perspectief: Gevalstudies. Gent: Academia Press. 63-72.

. 2014b. "Beloken blikvelden in de Lage Landen. Eenentwintigste-eeuwse receptie van Nederlandse vertalingen van Afrikaanse poëzie: Ingrid Jonker, Antjie Krog en Ronelda S. Kamfer." Y. T'Sjoen. 'Zoals een grens op de kaart.' Nederlandse literatuur in vergelijkend perspectief: Gevalstudies. Gent: Academia Press. 99-125.

. 2014c. "Sheila Cussons en Wilma Stockenström in de Nederlandse literatuur. Aanzetten voor een receptiestudie. Literair-institutionele positionering en kritische ontvangst van twee Zuid-Afrikaanse dichters in Nederland." Y. T'Sjoen. 'Zoals een grens op de kaart.' Nederlandse literatuur in vergelijkend perspectief: Gevalstudies. Gent: Academia Press. 127-149.

2015a. “Charl-Pierre Naudé en Gert Vlok Nel in Nederland en Vlaanderen. Laterale en verticale transnationale bewegingen van Afrikaanstalige schrijvers naar Nederlands en Engels." Tydskrif vir Geesteswetenskappe. [in print]

. 2015b. "'ek het die son geruik.' Gerrit Komrij's beeldvorming van de vroege poëzie van Breyten Breytenbach." Stilet. [submitted]

Viljoen, L. 2014. "Die rol van Nederland in die transnasionale beweging van enkele Afrikaanse skrywers." Internationale neerlandistiek 52(1): 3-26. 